\title{
Historical influence of soil and water management on sediment and carbon budgets in the United States
}

\author{
Eric T. Sundquist ${ }^{\mathrm{a}, *}$, Katherine Visser Ackerman ${ }^{\mathrm{a}}$, Robert F. Stallard ${ }^{\mathrm{b}}$, Norman B. Bliss ${ }^{\mathrm{c}}$ \\ a USGS, 384 Woods Hole Rd., Woods Hole, MA 02543, USA \\ ${ }^{\mathrm{b}}$ USGS, 3215 Marine St., Boulder, CO 80303, USA \\ ' SAIC, USGS/EROS, 47914 252nd St., Sioux Falls, SD 57198, USA ${ }^{1}$
}

The documented history of US soil and water management provides a unique opportunity to examine soil and sediment $C$ storage under conditions of changing management practices. Historical acceleration of erosion due to cultivation has been moderated by improved soil management. Increased construction of dams and locks has expanded areas of aquatic sedimentation in reservoirs and ponds. Enhanced historical sediment deposition rates have been documented in lakes and estuaries. All of these changes have an impact on terrestrial $C$ storage and turnover. The present-day $C$ budget associated with erosion and burial cannot be determined without quantifying the time-dependent changes due to past and present soil and water management.

Existing datasets are used with GIS and modeling techniques to estimate sediment and $C$ budget trends since the year 1700 in the conterminous US. To begin historical sediment budget scenarios representing effects of soil- and water-management practices were calculated. Soil erosion estimates for recent decades were derived from the US National Resources Inventory (NRI). Using estimates of historical cropland erosion yields (erosion rates per unit area) and cropland areas and distributions (derived from US census data), simplistic "hindcast" erosion scenarios were calculated for the years prior to the NRI estimates. Sedimentation rates compiled in the US Reservoir Sedimentation Survey Information System were used. Systematic relationships among these rates are applied to estimate historical sedimentation for the more extensive US National Inventory of Dams, and for lakes and ponds. Because the analysis uses a combination of diverse existing datasets, particular attention is devoted to methods of data integration that are consistent with the statistical character of the source data.

The analysis indicates that historical export of sediments to coastal areas is relatively insignificant, whereas substantial sediment deposition in upland areas is necessary to balance the histor- ical sediment budget. Relatively recent rates of sedimentation in lakes and impoundments appear to match or exceed rates of upland erosion, suggesting that a fraction of recent sediment transport is derived from channel and bank erosion, including remobilization of historically deposited alluvium and colluvium.

For each historical sediment budget scenario, models of $\mathrm{C}$ dynamics are applied to time-dependent accounting of $C$ in erosional and depositional environments. The $\mathrm{C}$ calculations begin with estimates of the $C$ content of soils at erosional and depositional sites based on the NRI soil database. Rates of soil C production, erosion, degradation, transport and burial are constrained by both sediment and $C$ mass-balance coupled to representations of landscape soil-C dynamics. Carbon burial in aquatic environments is calculated from estimates of composition and deposition rates of autochthonous and allochthonous sediment. It is found that cumulative amounts of $\mathrm{C}$ affected by historical erosion and deposition are comparable to amounts of cumulative soil $\mathrm{C}$ depletion estimated in previous studies that have not considered erosion and deposition.

The historical sediment budget scenarios imply a large historical transient of eroded and redeposited terrestrial sediments. An improved understanding of non-steady-state $C$ dynamics in these sediments is needed to estimate the net effect of erosion and deposition on the historical and present-day exchange of $C$ between the land and the atmosphere. The transient sediment pulse and accompanying biogeochemical and ecological responses have broader implications for management of water and ecosystems (e.g., to address effects of sedimentation and $\mathrm{N}$ loading on riparian zones and wetlands). Continuing investigation of these important topics will require more robust collaboration across disciplines and institutions.

\footnotetext{
* Corresponding author.

E-mail address: esundqui@usgs.gov (E.T. Sundquist).

1 Work Performed under USGS Contract 03CRCN0001.
} 